\title{
Urdimento
}

\section{A SUBPARTITURA CORPORAL NO PROCESSO DE CRIAÇÃO DO ESPETÁCULO BATATA!}

\author{
Leonardo Sebiani ${ }^{1}$
}

\section{Resumo}

A presente pesquisa propõe uma reflexão sobre a subpartitura corporal nos intérpretes-criadores do grupo baiano DIMENTI, durante o processo de criação do espetáculo "Batata!". O conceito de subpartitura foi elaborado por Patrice Pavis propõe a utilização das informações que servem como "bagagem" do intérprete. O objetivo da pesquisa é a apropriação do conceito de Pavis transportado para o corpo cênico utilizando como referencial teórico a Critica Genética de Cecília Salles. A analise corporal pretende reconhecer a importância da subpartitura dentro das Artes Cênicas.

Palavras-chave:subpartitura, processos de criação, corpo, artes cênicas.

\begin{abstract}
The aim of this study proposes a reflection on the bodily subscore of the performers of DIMENTI (a group of Salvador, BA, Brazil), during their creation process of "Batata!". The concept of subscore was presented by Patrice Pavis proposes the use of information that serves as the support for the performers. The objective of the research is to take Pavis's concept and transport it to the performing body. It will be used as a theoretical reference the Genetic Criticism of Cecilia Salles. The bodily analysis seeks to recognize the importance of subscore within the Performing Arts.
\end{abstract}

Keywords: subscore, creation process, body, performing arts.

\section{A subpartitura}

Dentro das artes cênicas contemporâneas a análise das informações dos intérpretes-criadores, tem oferecido um valor maior às possibilidades e à bagagem das informações provenientes dos corpos cênicos dentro dos processos criativos. Um dos aportes maiores são as informações que têm os corpos dos intérpretes, esseleque denominado por Bonfitto, de várias situações preestabelecidas, as quais ajudam a uma desestruturação e estruturação constante desses corpos estéticos sociais na cena contemporânea; para vários estudiosos essas informações são imprescindíveis. Pavis (2005: 89), chama-as de subpartitura:

${ }^{1}$ Leonardo Sebiani possui graduação em Atuação pela UNA (Costa Rica, 2003),

Licenciatura em Docência pela UNED (CR, 2006), Mestrado em Ciências do Movimento Humano pela UCR (CR, 2007), atualmente é Doutorando do PPGAC/UFBA. Tem experiência em Teatro,

Dança, Pedagogia e Ciência. Acadêmico da Escuela de Artes Escénicas, Universidad Nacional (Costa Rica) Doutorando PPGAC/ UFBA. 


\title{
Urdimento
}

\begin{abstract}
"Ela é essa sólida massa branca imersa sobre a qual se apóia o ator para parecer e permanecer em cena, tudo aquilo sobre o que ele baseia sua atuação. Trata-se do conjunto dos fatores situacionais (situação de enunciação) e das competências técnicas e artísticas sobre as quais o ator/a atriz se apóia quando realiza sua partitura".
\end{abstract}

Desde os mestres Stanislavski, Dalcroze e Duncan, a expressão de um gesto deve ser orgânico, único, verdadeiro. Esse apoio interno explorado pelos grandes mestres parece dar um suporte ao aparelho expressivo - ou seja, ao corpo. Para Pavis (2005: 91), "o ator toma referência e se apóia em uma série de pontos que formam a configuração e a estrutura de sua atuação". Tais pontos de apoio sustentam sua memória emocional e sinestésica, seu corpo pensante. Para Martha Graham o corpo deve estar treinado tecnicamente para vir a expressar-se. Ela procurava, assim como as técnicas de Ballet Clássico, treinar o músculo de tal maneira que, conhecendo o caminho, o corpo reagisse sem ter que pensar nisso - talvez esse fosse um "corpo pensante". Em teatro, o treinamento prepara o ator, o ensaio prepara a obra e a representação. $\mathrm{O}$ treinamento é, no processo de codificação de uma técnica, fundamental, pois é nele que o ator trabalha a si e à arte em si. $\mathrm{O}$ fato do treino não ter vínculo imediato com o resultado, permite um trabalho de elaboração e aprimoramento de instrumentos concretos e objetivos da arte do ator.

Dentro de um estilo de atuação adquirido ao longo dos anos de treino e de aculturação, importa observar como o tempo, a cultura e as técnicas corporais sedimentam-se no corpo do ator antes mesmo que ele entre em cena. "A subpartitura busca, é claro, o que está oculto na preparação do ator, o que existe antes de sua expressão visível e fixada na partitura da atuação, mas ela também já se encontra infiltrada e formada pela cultura ambiente" (PAVIS, 2005: 91-92).

Vislumbra-se, nessas informações, que a subpartitura é um elemento importante nos processos criativos e que é parte intrínseca na individualidade do sujeito e de sua cultura. A subpartitura possibilita discernir a importância de pesquisar essas informações e sua influência dentro da encenação, e ver assim o poder potencializador que adquire uma peça e seus processos dentro da análise das subpartituras de seus intérpretes.

No desenvolvimento das Artes Cênicas nos últimos tempos, o corpo teve uma participação crescente dentro das pesquisas e, como nos processos criativos, os pesquisadores procuraram não somente um corpo técnico, mas igualmente expressivo. Essa expressividade e capacidade de estruturação e desestruturação aumenta, quanto maior for a quantidade de informações possuídas pelo intérprete dentro de si (experiências de vida, técnicas, etc.) A cultura influencia o corpo e suas informações, ou 
seja, a subpartitura - a massa de conceitos acumulados e expostos nos corpos dos intérpretes, a qual está diretamente relacionada à sua cultura ou à cultura em que se desenvolve.

Poderíamos dizer que existe uma constante troca entre a cultura e o corpo, e que suas modificações vão-se dando com as modificações da sociedade num tempo e espaço determinado. Claro está que essa cultura e esse corpo tem uma história, já que existe uma memória, uma memória coletiva para eventos sociais e uma memória corporal pessoal e intransferível; segundo Fernandes (2004: 59), "a memória e história se recolocam também no corpo. Seja nos gestos miméticos que nos inscrevem numa tradição, seja nas marcas pessoais e intransferíveis que carregamos em nossos corpos". Isto é relatado também por Sant'Anna, (2004: 3), que pensa o corpo como "um território, um território tanto biológico quanto simbólico, processador de virtualidades infindáveis, campo de forças que não cessa de inquietar e conformar, o corpo talvez seja o mais belo traço da memória da vida". Verdadeiro arquivo vivo, inesgotável fonte de desassossego e de prazeres, o corpo de um indivíduo pode revelar diversos traços de sua subjetividade e de sua filosofia mas, ao mesmo tempo, escondê-los. Pesquisar seus secretos é perceber o quanto é vão separar a obra da natureza daquela realizada pelos homens: na verdade, um corpo é sempre biocultural, tanto em seu nível genético, quanto em sua expressão oral e gestual.

"Nosso objeto de estudo não é somente o corpo físico-biológico, nem apenas o corpo psicológico ou sócio-antropológico, mas o corpo do homem como um ser de culturas - um corpo moldado pela ação conjunta de todos os outros corpos que a cultura oferece. O corpo como um sítio arqueológico que permite inúmeras leituras semióticas, um corpo portador do biológico e dos textos da cultura” (BELLINI, 2001: 211).

Esse sitio arqueológico que é o corpo tem tantas cores e matizes maravilhosas que permitem aos artistas as mais variadas experiências dentro de seus processos criativos. Para Ostrower (1987: 5) "a natureza criativa do homem se elabora no contexto cultural". Todo individuo se desenvolve em uma realidade social, em cujas necessidades e valorações culturais se moldam os próprios valores de vida. No indivíduo confrontam-se, por assim dizer, dois pólos de uma mesma relação: a sua criatividade que representa as potencialidades de um ser único, e sua criação que será a realização dessas potencialidades já dentro do quadro de determinada cultura. Assim como num processo coletivo em dança é importante pensar também nos diálogos intercorporais e como eles podem acontecer de maneira não verbal, imagens são transmitidas de um corpo para o outro através do movimento da cabeça, do tronco e dos membros. Mesmo a linguagem verbal, com seus signos e significados, provoca imagens no corpo receptor. A palavra é imagética. "Nos 


\section{Urdimento}

processos coletivos de criação artística os corpos utilizam múltiplos artifícios em sua interação dialógica e para isso os sentidos do corpo - buracos do corpo vazado - são fundamentais" (SANCHES, 2006: 44).

O diálogo das imagens, e da informação cultural impregnada em nossos corpos, assim como a influência dos processos criativos coletivos é um cúmulo de tantas noções, deste modo a utilização de uma ou varias técnicas corporais afetam o contaminam os corpos.

Nosso corpo tem muitas informações adquiridas pelas técnicas corporais, já que foram criadas num momento determinado e com um objetivo determinado. Portanto, elas também refletem uma realidade do momento sociocultural. Por isso os corpos que passam pelas academias carregam várias informações, somandose àquela do cotidiano, ou seja, no uso social do corpo. "E assim que, com nosso uso social do corpo, é necessariamente um produto de uma cultura: o corpo foi aculturado e colonizado. Ele conhece somente os usos e as perceptivas para os quais foi educado" (BARBA e SAVARESE, 1995: 245). Essa educação designada por Barba e Savarese leva o corpo a comportar-se de um jeito determinado com base em suas informações. Numa sociedade desconhecida, leva o estrangeiro a procurar determinados signos comuns, e assim compreender e interpretar as informações e signos socioculturais, para não sofrer um estranhamento distanciador e subjetivo dessa determinada cultura.

Dentro da pesquisa cênica, devemos localizar o contexto do objeto a investigar; é assim, como dentro das informações predominantes a estudar, nas subpartituras dos intérpretes num processo de criação. É sua cultura imediata, como exemplifica Sanches (2006: 54), que realizou pesquisa sobre um corpo determinado - seu próprio corpo. Dispõe ele, que:

"A cena contemporânea é criada, apresentada e refletida nos corpos contemporâneos. Num processo criativo como este, realizado numa perspectiva multidisciplinar, envolvendo diferentes coreógrafos com suas múltiplas estéticas, entendo os corpos como complexos construídos num ambiente regido pela diversidade sociopolítica e cultural absorvendo os múltiplos valores deste ambiente. Os corpos nesta pesquisa são identificados nas manifestações e costumes da cultura baiana, o que resulta em criações artísticas onde é possivel perceber aspectos claros de uma cultura formada por diferentes etnias".

Tendo minha pesquisa como proposta à análise do espetáculo Batata! (2008) do grupo Dimenti, criada e feita por um corpo baiano com múltiplas informações, e influenciado diretamente por uma cultura plural e mestiçada como é a cultura baiana, fato de vital importância na leitura destes corpos solteropolitanos. Levando me a estabelecer uma questão, será que essa 


\section{Urdimento}

subpartitura sente-se afetada por determinada cultura? Segundo o mesmo Pavis (2005: 91), a subpartitura não é simplesmente uma estrutura controlada pelo ator em busca de sua partitura, ela é feita de normas culturais e de modelos de conduta dos atores e dá testemunho da marca da cultura sobre ele.

Apos tanto tempo esquecido, o corpo nas Artes Cênicas é finalmente colocado num lugar importante, contextualizado a partir dos conceitos de modernidade, pósmodernidade e contemporaneidade. Além disso, o corpo está inserido na discussão cientifica que trata de sociedade e cultura. Cada corpo possui suas historias, modificado e enriquecido pela cultura e sociedade, que, levado à cena, firma-se único e expressivo na sua subpartitura. Daqui que quero abranger com um olhar amplo esses corpos, múltiplos corpos cênicos, corpos das artes cênicas contemporâneas, como assegura Bonfitto (1999: 42): "agora, no contexto teatral, sabe-se que este não mais compõe-se de um teatro, mas de muitos teatros". Conseqüentemente, não existe uma concepção a respeito do corpo do interprete, mas sim diferentes concepções de corpo - muitos corpos.

\section{Dimenti}

O Dimenti tem desenvolvido uma pesquisa de linguagem desde a sua formação, em 1998. Isso implica um conjunto de interesses, princípios poéticos e modos de operação reconhecíveis e compartilhados pelo conjunto.

"O conjunto nada tem de fixo, já que está em constante processo de desenvolvimento, sendo reconfigurado a todo instante, pois as proposições do grupo buscam ser bastante dinâmicas. Como se trata de uma pesquisa continuada, muitas questões são retomadas e complexificadas ao longo dos anos de trabalho; isto causa modificações - de ordem conceitual e estrutural - em todas as obras cênicas do grupo que, desde o espetáculo de estréia O Alienista, está em atividade. Não trabalhamos preocupados com o surgimento de novidades a cada criação, mas sim em repensar constantemente alguns dos nossos focos de pesquisa artística, para formular diferentes questões criativas, muitas vezes, para os mesmos objetos" (ALENCAR, 2007: 78).

Desde a montagem de $\mathrm{O}$ Alienista, espetáculo inspirado no conto homônimo de Machado de Assis, o grupo Dimenti vem consolidando o desenvolvimento de uma linguagem baseada na pesquisa e no formato dos clichês estéticos e da corporeidade do Cartum². O grupo pesquisa, sobretudo, "produtos da indústria cultural - telenovela, programa de auditório, propaganda, musical da Broadway, cinema, produtos de entretenimento infantil-" (ALENCAR, 2007: 79), partindo desta conversão, nasce um olhar critico destes produtos da indústria cultural e, apoiando-se em estereotipias presentes neles e no inconsciente coletivo brasileiro.
${ }^{2}$ Cartum (do inglês cartoon) diz respeito a desenho animado e não a história em quadrinhos (HQ). Apesar de guardarem relações formais entre si, a investigação do Dimenti se debruça no corpo em movimento apresentado pelo desenho animado. Desde as primeiras obras criadas - 0 Alienista e Chá de Cogumelo - o Dimenti, além de investigar a construção narrativa e a corporalidade do desenho animado, faz citações no palco de títulos conhecidos como A Caverna do Dragão, Tazmania e Pink e 0 Cérebro. (ALENCAR, 2007: 79). 


\section{Urdimento}

Os processos de criação em Dimenti compõem um caldo de múltiplos "ingredientes", como eles mesmos se identificam. Trata-se de um agregado de percepções e apropriações; estas apropriações partem sempre do referencial de cada participante do grupo, numa atitude colaborativa, aproveitando a diversidade de experiências e informações geradas pelos intérpretes-criadores em conexão com os elementos compositivos do trabalho, utilizando a pluralidade como ferramenta e baseando-se nos critérios teórico-práticos do grupo.

\section{O corpo em Dimenti}

No Dimentios corpos dos intérpretes-criadores estudam a composição dos desenhos animados para chegar na conceição de um outro corpo, um corpo cartunesco com um risco físico constante, que é transformador de fronteiras corporais.

O corpo cartunesco tem vários aspetos, um deles utilizado recorrentemente são as variações abruptas de estado corpóreo, realizadas por corte seco. Não existe uma fluidez entre ações elas são um constante collage de mutações esporádicas. O corpo em Dimenti é movido por interrupções/ modificações bruscas, as quais requerem uma urgência no atendimento das intenções e objetivos cênicos, em um ambiente que está em permanente processo de descontinuidades e estranhamentos.

$\mathrm{Na}$ cena se observam corpos realizando ações simultâneas, as vezes incoerentes, discrepantes, contraditórias o desconectadas, que ajudam a clarear essa idéia de borrar fronteiras. E justo nesta procura de borrar fronteiras que nasce o conceito de "Corpo Borrado", o qual surgiu recentemente para dar nome ao o trabalho do grupo, como expõe Alencar (2007: 104):

"A expressão "corpo borrado", surgida recentemente na tentativa de nomear, numa metáfora-síntese, a organização criativa, ética e operacional do grupo ao longo dos anos de trabalho. Esse termo não procurar abarcar ou fixar a pesquisa artística do grupo, mas atende a uma demanda momentânea do grupo, podendo ser revisto posteriormente. De modo contíguo a esse estudo, um corpo borrado não reivindica uma identidade unificada num "eu" coerente, mas se transforma continuamente. Na busca de entender melhor o que eu mesmo venho produzindo, num processo de realizar e de se ver realizar, esse "corpo borrado" corresponde: 1) a um conjunto de procedimentos compositivos presentes na pesquisa artística do grupo; 2) a um tipo de corporalidade investigada nas minhas criações em dança; 3) aos acordos éticos presentes na configuração da equipe de trabalho do Dimentimetodologia de criação e de produção - e suas implicações afetivas". 
Este corpo borrado, não é fixo, ele é dinâmico, permeável e ultrapassa os conceitos de território e de fronteira:

"A idéia de borrar demarcações traz à tona a sólida idéia de território, mas não para reforçá-la e sim para dinamizar um processo de identificações que problematizam tradicionais oposições binárias [… A criação desse espaço fronteiriço, intersticial se irmana à discussão sobre identidade cultural $e$ hibridismo, procurando justamente descartar certas perspectivas essencializadoras sobre identidade enquanto um constructo fixo".

(ALENCAR, 2007: 105)

A idéia de borrão vem se desenvolvendo a traves dos trabalhos do grupo, mas foi a partir do IV Ateliê de Coreógrafos Brasileiros (2005), com a criação da A Lupa, que Alencar explora movimentações que criam uma tensão e correspondem à identificação cartunesca nos corpos dos interpretes. Esses corpos transitam entre "o acidente e a construção, a impostação e o relaxamento, entre o 'estado de cena' e o 'estado de coxia”" (ALENCAR, 2007: 107). A atitude destes corpos é de uma displicência construída e gerando uma simultaneidade de ações desconexas no corpo. Um corpo cheio de torções em situações desconexas obrigam a os corpos na cena a uma manipulação e articulação, a idéia seria gerar um "nó" com eles e neles, dando como resultado formas grotescas do corpo em uma situação pouco habitual.

Dentro de essa simultaneidade, constantes variações nos estados corporais, eles não tem uma conexão fluida, esta passagem é repentina, em um nexo-causal, o que Dimenti chama de jogo de "interruptor".

Assim o corpo é utilizado em Dimenti como um corpo borrado, que demarca as estratégias do grupo, como assegura Alencar (2007: 110):

"A idéia de um corpo borrado ainda encerra um pressuposto ético que diz respeito ao modo como organizo os meus processos pedagógicos de criação e ao trabalho colaborativo no Dimenti. No grupo, não existe um único programa de preparação artística para as criações. São realizadas leituras, conversas, coleta de referenciais imagéticos (vídeos, músicas, fotos e outros), produções literárias que possam atender a cada questão específica com a qual nos deparamos. Muitas vezes os encontros e ensaios se resumem a longas conversas e avaliações sobre alguma questão do grupo ou sobre nosso entorno cultural." 


\section{Urdimento}

\section{A análise do Processo Criativo}

Como base para o estudo do grupo, utilizou-se o trabalho Batata! (2008), que possui como matéria-prima textos de autores baianos inspirados no universo de Nelson Rodrigues; como metodologia de análise, foi utilizada a observação e a avaliação dos corpos e de suas informações; para a análise do processo criativo, utilizaram-se as anotações das impressões durante os ensaios e entrevistas com o diretor do grupo sobre o caminho que se pretendia seguir.

Neste percurso de acompanhar o trabalho com um olhar externo e estrangeiro foi bastante gratificante, pois vários conceitos e paradigmas foram reestruturados - o trabalho de apropriação dos textos por Dimenti, tem como primazia a corporeidade Cartum e o clichê, os quais encaixaram-se muito bem com as propostas dos autores. O Dimenti é um grupo consolidado e a maioria de seus integrantes participa desde sua fundação no ano de 1998. Sendo um trabalho totalmente colaborativo, o diretor Jorge Alencar, conhece e reconhece a heterogeneidade dos corpos e, por sua vez, as possibilidades de cada um deles, ou seja, reconhece o conceito de Pavis, com relação à bagagem que cada corpo possui e sabe como cada um pode desempenhar e aproveitar a proposta individual dentro da coletividade dimentiana.

No processo criativo o grupo faz seções de leituras de textos - tanto daqueles que têm a ver com o tema diretamente, quanto de outros que não atendem necessariamente à proposta, mas que funcionam como base de discussões das quais saem múltiplos jogos cênicos. Cada um aponta a possível leitura de um texto, frase, gesto ou movimento e cada um indica algo e apóia o outro no desempenho da proposta. No processo descrito por Salles (2008: 91) com a Companhia 2 do Ballet da Cidade de São Paulo durante o 2005, "Os limites ou restrições são enfrentadas com dificuldade e permanentemente transformados em desafios"; para o Dimenti, os limites sãouma fronteira pela qual eles transitam, porém limites ou restrições são dadas como regras de jogos, acompanhadas por um humor característico dimentiano, onde o desafio não é a partir da restrição, e sim, à partir do jogo. Por exemplo: no espetáculo utilizavam-se copos de plástico no palco e era uma regra não tirar os copos; esse ponto era visto como parte de um jogo e não como uma restrição; aqui compartilho com Salles que reconhece no discurso de Klaus a importância "de estar aberto a" (VIANNA apud SALLES, 2008: 91). Para mim, o Dimenti possui abertura a coisas novas e, sobretudo, ao jogo cênico corporal de onde partem as propostas criativas.

Dentro da proposta de Dimenti, todo é um território de câmbios, nada é fixo, pois dentro dos ensaios existe a possibilidade de criar-se 
inúmeros espetáculos. No processo de "Batata" trabalhou-se sob a proposta de ingredientes, ou seja, de jogos criativos, os quais foram identificados através das leituras dos textos de Nelson Rodrigues, da apropriação dos mesmos, de utilização das rubricas do autor, da imersão no universo do autor onde, por exemplo, num momento era trabalhado o ingrediente o "Abraço a Deus", que era a proposta de ver no outro a Deus e abraçá-lo tanto, que nunca quisesse soltá-lo e o resto dos colegas insistissem em soltá-lo, com força, até conseguir a separação. Nos textos de Nelson, assim como o exemplo colocado se expõe as paixões desenfreadas que levam em algumas ocasiões, a situações surreais.

Em concordância com a proposta analisada por Salles para a Companhia 2, os elementos externos tiveram uma importância conforme o corpo do intérprete tinha mais contato com ele e com sua criatividade. No caso de Batata! copos de plástico; flores de pelúcia para crianças; louças verdes de escola, de diferentes tamanhos e giz, foram incorporadas às propostas durante a criação e na proposta final.

Dentro da proposta de acompanhamento do processo criativo pude apreciar e reconhecer momentos desse gesto inacabado, onde para mim foi importante "compreender o ato criador nos leva, certamente, à constatação de que uma possível morfologia do gesto criador precisa da beleza da precariedade de formas inacabadas e da complexidade de sua metamorfose" (SALLES, 2004: 60), a partir das individualidades e dos universos de cada um desses corpos dos intérpretes-criadores de Dimenti; do universo sensível do processo de criação e, de como o diretor do grupo consegue aproveitar as subpartituras de cada um deles; seus aportes num caminho de construção de ingredientes e regras a partir de uma corporeidade cartunesca; e a releitura dos clichês e estereotipias dos mecanismos de consumo social e da apropriação de textos e universo comunicacional.

Neste processo, meu olhar como ente externo foi proveitoso ao conhecimento da tendência do grupo e dos estudos anteriores ao trabalho de Batata! e da quantidade de material que foi excluída, pois no momento do recorte do diretor, ele se baseia em que "Tudo vale, depois conta uma boa orientação e uma boa edição" (ALENCAR apud MOLINA, 2006: 63). Essa edição parte do reconhecimento desse corpo descrito por Bellini, em que um universo de informações impregnadas por uma cultura é o que nos oferece os intérpretes-criadores de Dimenti, numa heterogeneidade implícita em nossa contemporaneidade, e assim como reconheço na proposta do grupo, um borrar fronteiras nas artes cênicas contemporâneas, dando um novo significado ao corpo e aos processos criativos em contínuo acabamento ad infinitum. 


\section{Urdimento}

\section{Referências bibliográficas}

ALENCAR, Jorge Luiz. Do cisne-barbie ao cisne asmático: comicidade e subversão performativa de identidade em chuá - releitura cênica do balé $\mathrm{O}$ lago dos cisnes feita pelo grupo Dimenti. Dissertação de Mestrado, PPGAC, UFBA: Salvador, BA, Brasil: 2007.

BARBA, Eugenio; SAVARESE, Nicola. A arte secreta do ator: dicionário de antropologia teatral. São Paulo: Editora da Unicamp, 1995.

BELLINI, Magda. Dança e diferença: duas visões, Corpo, dança e deficiência: a emergência de novos padrões. Rio de Janeiro: UniverCidade, s/d: Lições de dança, $n^{\circ} .3$, p. 211.2001.

BONFITTO, Mateo. O corpo no trabalho do Ator. Salvador, BA: UFBA: Revista Repertório: Ano 2, nº 3, 1999.2

FERNANDES, Ciane. Pina Baush e o Wuppertal Dança-Teatro: Repetição e transformação. Editora Hucitec: São Paulo, 2000.

MOLINA, Alexandre José. Caleidoscópio de um processo colaborativo em dança. Diálogos Possíveis. Salvador: FSBA, nº 10, p. 57-68, jan./jun. 2007.

OSTROWER, Fayga. Criatividade e processos de criação. Petrópolis: Vozes. 1987.

PAVIS, Patrice. A análise dos espetáculos. São Paulo: Perspectiva, 2005.

SALLES, Cecilia. Gesto Inacabado: processo de criação artística. $2^{\circ}$ ed. São Paulo: Annablume, 2004.

SALLES, Cecilia. Crítica Genética: fundamentos dos estudos genéticos sobre o processo de criação artística. $3^{\circ}$ ed. São Paulo: EDUC, 2008.

SANCHES, Antrifo. Lá ele, devaneios, memórias e estados de corpo em três processos coreográficos. Dissertação de mestrado PPGAC, UFBA: 2006.

SANT'ANNA, Denise. É possivel realizar uma historia do corpo? Corpo e historia. Carmen Lúcia Soares (org.). Campinas, São Paulo: Autores Associados, 2004. 